\title{
Molecular PHylogenetics of Limonium AND related genera (Plumbaginaceae): BIOGEOGRAPHICAL AND SYSTEMATIC IMPLICATIONS ${ }^{1}$
}

\author{
M. Dolores Lledó, ${ }^{2,4}$ Manuel B. Crespo, ${ }^{3}$ Michael F. Fay, ${ }^{2}$ And \\ MARK W. CHASE ${ }^{2}$
}

${ }^{2}$ Jodrell Laboratory, Royal Botanic Gardens, Kew, Richmond, Surrey, TW9 3DS, UK; and ${ }^{3}$ CIBIO (Instituto de la Biodiversidad), Universidad de Alicante, P.O. Box 99, E-03080 Alicante, Spain

\begin{abstract}
Phylogenetic relationships within Limonium (Plumbaginaceae) are evaluated using sequence data from three plastid regions ( $r b c L$, the $\operatorname{trn} L$ intron, and the $\operatorname{trn} L-t r n F$ intergenic spacer). Sixty-six species representing the major genera of Staticoideae, including representatives of all sections and genera formerly included in Limonium, have been analyzed using four species of Plumbaginoideae as an outgroup. Analyses of each separate and combined data set yield similar results. Afrolimon is embedded in Limonium and related to L. vulgare, the type of Limonium. Limonium is split into two major clades corresponding to subgenera, but otherwise the current infrageneric classification proved to be artificial. Some groups restricted to particular areas can be recognized, and their synapomorphies are discussed. The presence of an isolated taxon in the Canary Islands is used as a calibration point for age estimates of the major events in the genus, including migrations to the Southern Hemisphere, the Canary Islands, and Asia. The rapid radiation of Limonium in the Mediterranean basin appears to coincide with the desiccation of the Mediterranean Sea in the Messinian (late Miocene).
\end{abstract}

Key words: biogeography; Canary Islands; Limonium; Messinian; molecular phylogenetics; nonparametric rate smoothing (NPRS); Plumbaginaceae; $r b c L ; \operatorname{trnL}$ intron; $\operatorname{trn} L-F$ spacer.

Plumbaginaceae are a cosmopolitan family well represented in temperate zones of the Northern Hemisphere and showing preferences for arid or saline, often coastal, environments $(\mathrm{Ku}-$ bitzki, 1993). The Angiosperm Phylogeny Group classification of flowering plants (APG, 2003) included them in a broadly defined order Caryophyllales, together with other families adapted to extreme environments including oligotrophic soils (e.g., Droseraceae), arid zones (e.g., Cactaceae and Portulacaceae), and soils with high salt content (e.g., Amaranthaceae and Tamaricaceae).

Phylogenetic studies of Plumbaginaceae based on plastid DNA sequences and morphological data have been produced recently (Lledó et al., 1998, 2001). These studies confirmed the classification of Plumbaginaceae into two subfamilies, Plumbaginoideae and Staticoideae, well differentiated by morphological, chemical, and molecular characters. Plumbaginoideae comprise four genera, of which Plumbago, with approximately 20 species, is the largest. Staticoideae are morphologically more diverse. More than $85 \%$ of the species are in three genera, Limonium, Armeria, and Acantholimon, and the remaining species belong to monotypic or small genera split from Limonium and Acantholimon, although the status of these genera is not clear yet, as Kubitzki (1993) pointed out.

Recent systematic and phylogenetic studies of Limonium lack a global perspective, having been based on specific geographic areas (Ingrouille, 1984; Erben, 1993) or individual sections or groups that are putatively monophyletic (Lledó et

\footnotetext{
${ }^{1}$ Manuscript received 15 September 2004; revision accepted 24 March 2005.

The authors thank Arnoldo Santos Guerra (La Orotava Botanic Garden, Tenerife, Spain) for providing plant material of some Canarian species of Limonium, Michael O. Dillon (Field Museum, Chicago, USA) for supplying samples of Bakerolimon plumosum, and Kingsley Dixon (Kings Park and Botanic Garden, Australia) for Muellerolimon salicorniaceum. Funding for this project was provided by the Royal Botanic Gardens, Kew, and Consellería de Educación y Ciencia (Comunidad Valenciana, Spain).

${ }^{4}$ E-mail: 1.1ledo@kew.org.
}

al., 2003; Karis, 2004). The latest comprehensive accounts for the family and Limonium were published by Boissier (1848, 1859), and later authors have followed his system with only small alterations (Hooker, 1876; Pax, 1889). Boissier divided Limonium (former Statice, nom. rej. vs. Armeria; Greuter et al., 2000: 268) into 13 sections belonging to two main groups: "corolla polypetala" with eight sections and "corolla gamopetala" with four sections plus two others published at a later date (Table 1). Only two sections of the original corolla gamopetala, L. sect. Polyarthrion and L. sect. Siphonantha, are still included in Limonium (see Lledó et al., 2003, for a review of this group), although phylogenetic relationships of these new genera to other members of Staticoideae have not yet been assessed. Within the corolla polypetala group, only $L$. sect. Circinaria is currently separated from Limonium as genus Afrolimon.

The most recent attempt to clarify the taxonomy of Limonium was made by Pignatti $(1971,1972)$, who rearranged the genus for Flora Europaea. Pignatti divided the European taxa in three subgenera. Limonium subgenus Pteroclados (equivalent to the section with the same name) has approximately 18 species mostly endemic to the Canary Islands. Limonium subgenus Myriolepis was created to include three sections ( $L$. sects. Myriolepis, Siphonantha, and Polyarthrion), all of them members of Boissier's corolla gamopetala group. Finally, Pignatti $(1971,1972)$ placed the remainder of the European sections in a large unstructured $L$. subgenus Limonium, leaving African, American, and Asiatic species out of his system. In addition, nomenclature of the genus is also obsolete. Most of the sectional names were originally published under the former generic name Statice. Although some names have been consequently combined under Limonium (e.g., for European groups), a large number of sections are still based on dubious nomenclature. In our discussion, we refer to sections and subsections originally accepted by Boissier $(1848,1859)$ or by their generic name. We do not follow the subgeneric arrange- 
TABLE 1. Infrageneric classification of Limonium (former Statice) according to Boissier (1848), plus later additions.

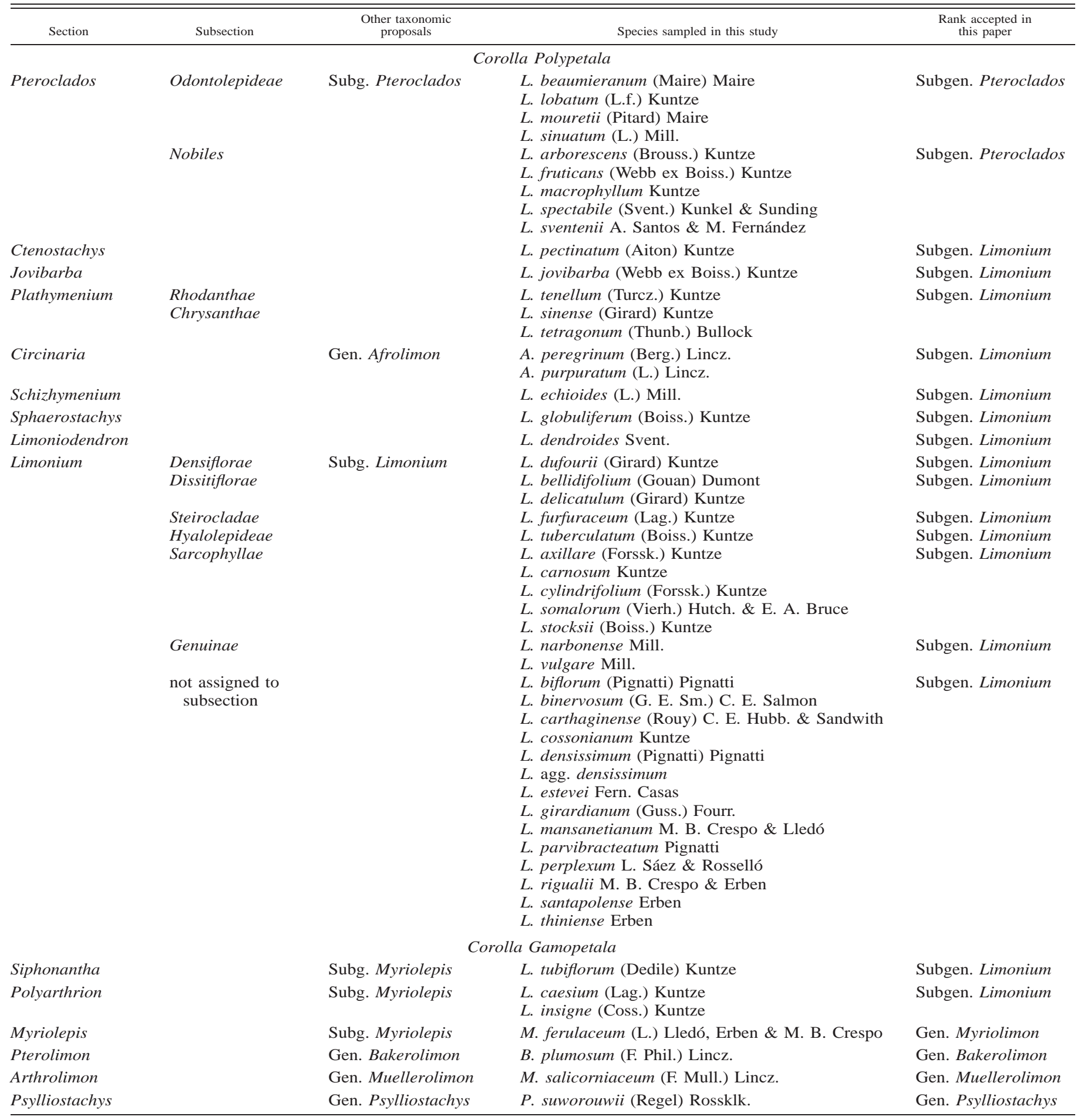

ment proposed by Pignatti because it excludes non-European sections, which only makes discussions more problematic to follow.

Despite the systematic and taxonomic confusion around $\mathrm{Li}$ monium and Plumbaginaceae in general, two aspects of the family, breeding systems and phytochemistry, are better known. Phytochemical studies (Harborne, 1967; Hanson et al.,
1994) have confirmed the differences between subfamilies and among Southern and Northern Hemisphere groups. Nevertheless, the lack of a robust systematic and phylogenetic framework makes interpretation of these results speculative. Breeding systems were extensively studied by Baker (1948, 1953a, b, 1966), who has been influential in the development of evolutionary and biogeographical hypotheses for the family, in- 
cluding the dispersal of genera related to Limonium to the southern continents (Afrolimon, Bakerolimon, and Muellerolimon). Using all available information (morphology, breeding systems, chorology, and karyology), Baker (1948) made the first attempt to clarify relationships among genera and tribes in the family. His results were obviously limited by the amount and types of data available at that time, and in the light of new molecular data these have been shown to be only partially correct (Lledó et al., 2001). He also studied the evolution of Limonium in more detail (Baker, 1966). Heterostyly, although typical in Plumbaginoideae, is also present in L. subsect. Genuinae (Baker, 1966), whereas pollen/stigma dimorphism and self-incompatibility, common within Staticoideae, are widespread in Limonium.

Facultative apomixis is common in Limonium, whereas truly sexual species are infrequent (e.g., L. sects. Polyarthrion and Pteroclados); sexual groups usually display fewer species than the apomictic ones. Hybridization, apomixis, and polyploidy in L. subsects. Densiflorae, Dissitiflorae, and Steirocladae are putatively key factors in the radiation of Limonium in areas such as the western Mediterranean basin. As a consequence, a large number of microspecies have been described, making difficult attempts to clarify the taxonomy of the group (Cowan et al., 1998).

One of the advantages of constructing molecular trees is the possibility of estimating the ages of lineages. The calibration of molecular trees is usually based on the fossil record or specific events that can be dated (e.g., presence of lineages on oceanic islands; Richardson et al., 2001). Plumbaginaceae have not been the focus of any extensive fossil research, and even pollen records are restricted to Quaternary strata (Godwin, 1956). Despite the lack of fossil information, the presence of phylogenetically isolated lineages on a volcanic archipelago, the Canary Islands, can be used as a calibration point. The Canary Islands are too close to the African continent to behave as a truly oceanic archipelago (110 km for the closest island, Fuerteventura, and $460 \mathrm{~km}$ for the most distant island, La Palma). The geomorphology of the Canary Islands has been extensively studied, as well as biogeography and colonization patterns (see Juan et al., 2000, for a review). The archipelago was formed by a series of volcanic periods that started approximately 20 million years ago (mya). There are three groups of Limonium present in the island flora, of which $L$. sect. Pteroclados and L. sect. Ctenostachys are not exclusive to the Islands. The monotypic and morphologically atypical $L$. sect. Limoniodendron (L. dendroides), which is a small tree or shrub only found on La Gomera, does not seem to be closely related to any other taxa. This island, formed approximately 10 mya (Juan et al., 2000), is the only island in the archipelago that has been without major volcanic activity for the last 4 million years. The age of the island can be used as a reasonable minimal age for $L$. dendroides to calibrate the tree, assuming that the intervening volcanic activity did not eliminate the flora.

In this study, DNA sequences for three plastid regions for species from all sections of Limonium plus representatives of the main genera of Plumbaginaceae are used to analyze relationships within Limonium. In addition, we include a large number of sexual and agamospermous microspecies from eastern Spain. The three plastid DNA regions, rbcL, trnL intron, and $t r n L-t r n F$ intergenic spacer (hereafter the $t r n L-F$ region), have been previously used to study phylogenetic relationships within the family and are variable enough to elucidate species- level relationships in Plumbaginaceae (Lledó et al., 1998, $2000,2001)$. The three main goals of this study are: (1) evaluation of the monophyly of Limonium and relationships with related genera; (2) investigation of relationships of agamospecies to sexual species, and (3) use of a molecular clock to estimate when these radiations took place.

\section{MATERIALS AND METHODS}

Plant material and sequencing-We selected 66 species of Staticoideae, including at least one species from each of the sections Boissier included in the former Statice and an exhaustively sampled set of Limonium microspecies from coastal areas of Alicante and Valencia (eastern Spain). Four species of Plumbaginoideae, sister group of Staticoideae (Lledó et al.,1998, 2000, 2001), were used as an outgroup (Table 1). Plant material was obtained from fresh tissue, silica gel-dried material (Chase and Hills, 1991), and seeds or leaf fragments obtained from herbarium specimens (Savolainen et al., 1995; Fay et al., 1998). DNA extraction and sequencing of all three regions were performed using standard techniques described in Lledó et al. (1998, 2000).

Phylogenetic analysis - Trees were inferred for $r b c L$, the $\operatorname{trn} L$ intron, the trnL-F spacer, and all data sets combined. For the $\operatorname{trn} L-F$ region, sequences were aligned using the Clustal option of Sequence Navigator (Applied Biosystems, Warrington, Cheshire, UK), and this first alignment was then optimized by eye following the recommendations of Kelchner (2000). Insertions and deletions were not coded as separate characters and thus were not included in the analyses because they did not provide additional support for groups with only low bootstrap percentages. Heuristic analyses were performed with PAUP* $4.0 \mathrm{~b} 10$ (Swofford, 2003) under equal weights, using 1000 random taxon additions and subtree pruning regrafting (SPR) and MulTrees on, but holding only 10 trees per replicate to reduce time spent swapping on a large number of trees. Subtree pruning regrafting has been shown to give similar results to tree bisection-reconnection (TBR), reducing the time of analysis (Salamin et al., 2003). Trees from all replicates were then used as starting trees for a final round of heuristic search, with a tree limit of 10000. Clade support was determined by bootstrap analysis (yielding bootstrap percentages, BP; Felsenstein, 1985) with 1000 replicates and SPR swapping but holding only 10 trees per replicate.

For four taxa, only one region could be amplified (trnL-F for L. jovibarbum and Goniolimon tataricum and rbcL for L. cylindrifolium and L. tubiflorum). To assess the effect of this number of missing characters in the final matrix, the combined analysis was performed with all terminal taxa (70 in total) and again with those for which both regions were present (66 in total).

Molecular clock calibration-Rate heterogeneity among lineages was calculated for the combined matrix excluding the four taxa missing for $r b c L$ or $\operatorname{trnL}-F$ (66 taxa including the outgroup) using the likelihood ratio test (Felsenstein, 1981). The likelihoods of constrained and unconstrained topologies were estimated, and a molecular clock was rejected. The TVM $+\mathrm{I}+\mathrm{G}$ model was chosen as the most appropriate using ModelTest version 3.06 (Posada and Crandall, 1998). The nonparametric rate smoothing method (NPRS; Sanderson, 1997) was applied to produce ultrametric trees with maximum likelihood (ML) and maximum parsimony (MP) branch lengths, using TreeEdit version 1.0a10 (Rambaut et al., 2000). We fixed the split between $L$. dendroides and the core-Limonium clade at 10 mya (the age of La Gomera; Fig. 2). We also determined confidence intervals for this date for both MP and ML by keeping the tree fixed and using 100 replicates of the bootstrap.

\section{RESULTS}

Combined analysis - When each data set was analyzed separately (trees not shown), the results obtained were similar to that from the combined analyses, but both BP and resolution were greater in the combined analysis. Results from each separate analysis did not show any incongruence supported by 
TABLE 2. Tree and matrix statistics for each plastid region and combined data sets.

\begin{tabular}{|c|c|c|c|c|c|c|c|c|}
\hline $\begin{array}{l}\text { Region/s } \\
\text { analyzed }\end{array}$ & No. taxa & No. characters & $\begin{array}{l}\text { No. variable } \\
\text { characters }\end{array}$ & $\begin{array}{c}\text { No. informative } \\
\text { characters }\end{array}$ & No. trees & $\begin{array}{c}\text { Tree } \\
\text { length }\end{array}$ & $\begin{array}{l}\text { Consistency } \\
\text { index }\end{array}$ & $\begin{array}{l}\text { Retention } \\
\text { index }\end{array}$ \\
\hline $\operatorname{trn} L$ intron & 68 & 651 & 276 & 167 & $>10000$ & 547 & 0.68 & 0.79 \\
\hline $\operatorname{trn} L-F$ spacer & 68 & 523 & 252 & 152 & $>10000$ & 490 & 0.69 & 0.83 \\
\hline$r b c L$ & 68 & 1299 & 457 & 223 & $>10000$ & 992 & 0.59 & 0.66 \\
\hline Combined & 70 & & & & 1440 & 2090 & 0.63 & 0.73 \\
\hline Combined (exc. missing) & 66 & & & & $>10000$ & 2064 & 0.62 & 0.72 \\
\hline
\end{tabular}

BP. Statistics for all single and combined analyses are given in Table 2.

The matrix was 2533 characters long with 995 variable characters $(39.28 \%)$, of which $543(21.43 \%)$ were potentially phylogenetically informative. When all 70 taxa were included, analysis produced 1440 trees of 2090 steps (consistency index, including all characters, $\mathrm{CI}=0.63$; retention index, $\mathrm{RI}=$ 0.73 ), one of which is shown on Fig. 1. Limonium forms a monophyletic group with Afrolimon (BP 60) embedded in it. Limonium sect. Pteroclados (BP 100) is sister to a large clade (BP 97) in which $L$. dendroides is sister to $L$. pectinatum- $L$. jovibarba (BP 100) and the core-Limonium clade. Within core Limonium, L. subsect. Sarcophyllae is polyphyletic, and $L$. cylindrifolium and $L$. carnosum are not related to the rest of the subsection (L. stocksii, L. somalorum, and L. axillare; BP 55); the group formed by $L$. sect. Polyarthrion (L. insigne-L. caesium) and L. tuberculatum has BP 99; Afrolimon (BP 84) is embedded in a clade with $L$. subsect. Genuinae (BP 98), which also includes $L$. carnosum ( $L$. subsect. Sarcophyllae) and $L$. globuliferum (L. sect. Sphaerostachys). Limonium sect. Plathymenium (BP 100) is sister to L. bellidifolium (BP 82), and the taxa from southeastern Spain form a clade divided in two groups (BP 92 and 52). Some genera formerly included in Limonium are related to other genera of Staticoideae. Bakerolimon and Saharanthus are sister to the clade formed by $M y$ riolimon and Armeria-Psylliostachys (BP 95); Muellerolimon is related to Goniolimon (BP 100), and this clade is sister to Dictyolimon, Cephalorhizum, and Acantholimon (BP 96). When the four taxa missing for $t r n L-F$ or $r b c L$ were excluded, the analysis produced 10000 trees of 2017 steps $(\mathrm{CI}=0.64$, $\mathrm{RI}=0.73$; Table 2). The exclusion of taxa with missing characters did not change the relationships among the remaining taxa (results not shown).

Tree calibration-The confidence intervals obtained gave a standard deviation of 0.88 (MP)-0.98 (ML) mya. The calibration of the $L$. dendroides node at 10 mya gave estimated ages of 18.84 (MP)-16.94 (ML) mya for the split between subfamilies Staticoideae and Plumbaginoideae (node a). Limonium sect. Pteroclados had an estimated age of 7.16 (MP)-6.74 (ML) mya (node d), and the radiation of microspecies in the Mediterranean basin started about 6.86 (MP)-7.18 (ML) mya (node c). The colonization of the Southern Hemisphere was dated at 16.68 (MP)-15.99 (ML) mya for Aegialitis in Australia and Asia (node b), 8.31 (MP)-9.55 (ML) mya for Bakerolimon in South America (node 1) and 2.94 (MP)-3.56 (ML) mya for Muellerolimon in Australia (node m). Estimated ages for other nodes in the tree are provided in Table 3 and shown in Fig. 2.

\section{DISCUSSION}

Subfamily Staticoideae - Relationships among genera within Staticoideae have already been discussed in previous papers
(Lledó et al., 1998, 2000, 2001). Only five new genera have been added for this analysis (Afrolimon, Cephalorhizum, Muellerolimon, Bakerolimon, and Myriolimon), the last three of which are former members of the Limonium corolla gamopetala group, although not related to each other. Myriolimon and Bakerolimon are in a clade with other genera with filiform stigmas, including Armeria, Psylliostachys, and Saharanthus (BP 95), a North African genus thought previously to be related to Limoniastrum (Crespo and Lledó, 2000). Relationships among these genera are not supported. Myriolimon, with only two species, is a western Mediterranean genus recently described (Lledó et al., 2003, in press), and the molecular results agree with the morphological, karyological, and phytochemical data that lead to its separation from Limonium. Bakerolimon from the desert regions of Peru and Chile was described to include the monotypic $L$. sect. Pterolimon (Linczevski, 1968). The last gamopetalous genus, the Australian Muellerolimon (= L. sect. Arthrolimon; Linczevski, 1982) is related to Goniolimon and placed in a clade (BP 100) that includes eastern genera with capitate/cylindrical stigmas.

Based on floral characters and gross morphological similarities (leafless shrubs with small flowers), Baker (1953b) thought that Bakerolimon was related to Muellerolimon. According to his ideas, these two genera were remnants of an ancient stock of Staticoideae that still possessed ancestral characters such as capitate stigmas as opposed to the filiform ones in the more recently evolved taxa in Limonium. Baker suggested that populations of an ancestral taxon migrated between western Australia and Patagonia through a temperate Antarctic as late as the Eocene (Baker, 1953b). When the Antarctic land bridge closed, the two populations evolved separately and now have distinct features despite their gross morphological similarities (e.g., a ribless calyx in Muellerolimon but with longexcurrent plumose nerves in Bakerolimon). The third Southern Hemisphere genus, Afrolimon ( $=L$. sect. Circinaria), a small group with approximately 10 taxa from the Cape Region, also with capitate stigmas, was seen by Baker (1953a) as a corroboration of the ancestral status of these three isolated genera. These Southern Hemisphere taxa are in fact not exclusively related to each other in our trees, and according to our time estimates (Fig. 2) their migrations to the Southern Hemisphere took place at different times. Our trees do not rule out the possibility that these taxa have independently retained plesiomorphic traits rather than developing them independently.

Cephalorhizum is related to Dictyolimon and Acantholimon in all our analyses. This relationship is not surprising. Staticoideae have two main centers of diversity. Whereas Limonium and related taxa have a greater number of species in the western Mediterranean, the group of genera related to Acantholimon diversified in the mountainous areas of the Middle East, the Balkans, and southwestern and central Asia (Rechinger, 1974). A number of monotypic genera have been described in the last 40-50 years (Kubitzki, 1993), but their va- 


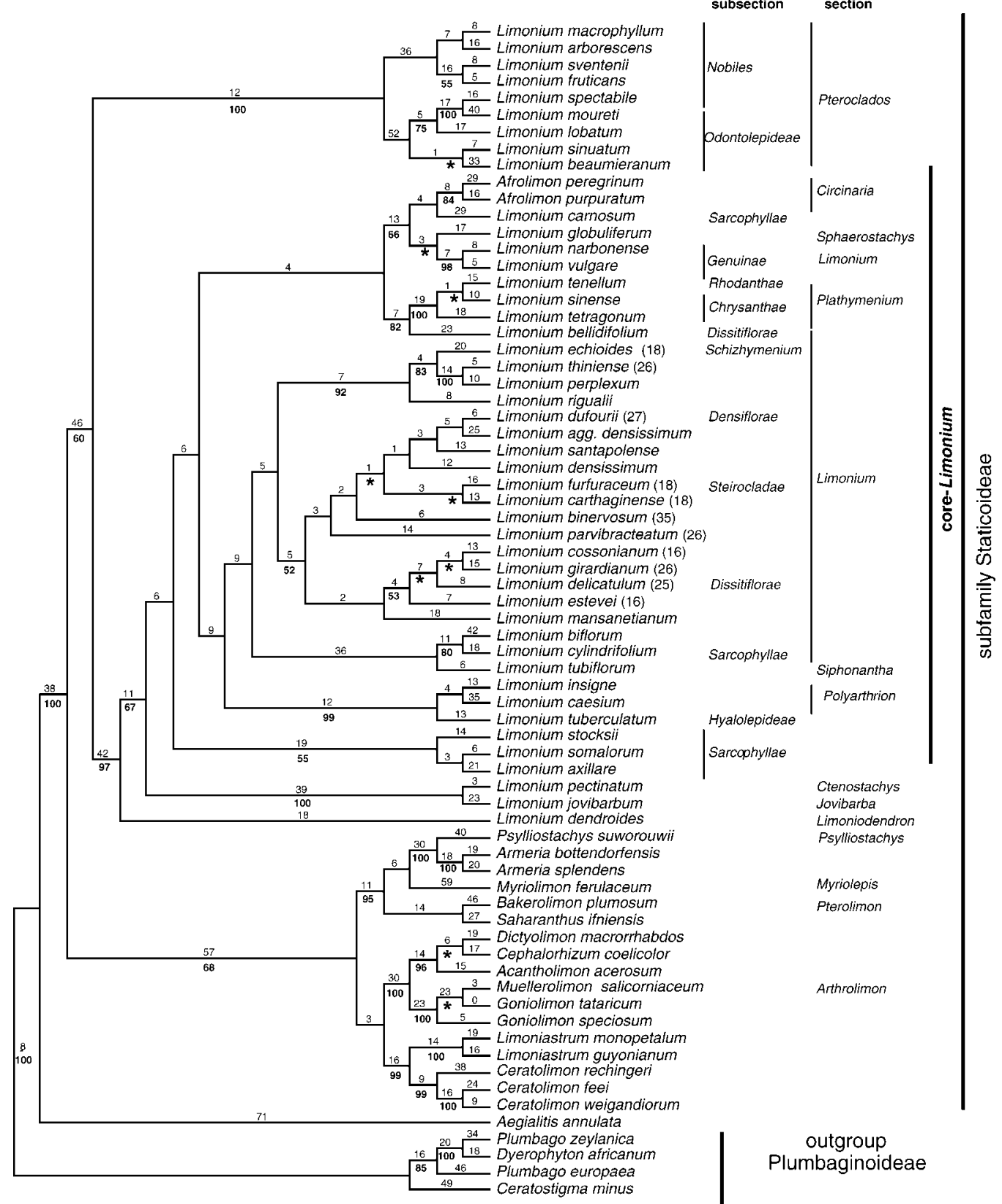

Fig. 1. One of the most parsimonious trees found with combined $r b c L$ and $t r n L-F$ data. Fitch branch lengths (DELTRAN optimization) are shown above the branches, and bootstrap percentages (BP) are shown below. Clades not present in the strict consensus tree are marked with an asterisk. Numbers after species names indicate chromosome counts. Infrageneric classification according to Boissier $(1848,1859)$. Some species have not been assigned to any section or subsection because they were only recently described or not specified in the original publication.

lidity has not been assessed in this study due to a lack of material suitable for DNA extraction.

Atlantic sections-The sections of Limonium previously considered as the most morphologically distinct form a grade relative to the rest of the genus. This is similar to the patterns observed in Moraea (Iridaceae; Goldblatt et al., 2002). Limonium sects. Pteroclados, Limoniodendron, and Jovibarbal Ctenostachys are successive sister clades to the rest of the genus, but not all of these relationships have high BP. This grade is primarily found in northern and western Africa and the Canary Islands.
Limonium sect. Pteroclados consists of approximately 18 recognized species, nine of which were included in this study; they form a well-supported clade (BP 100; Fig. 1). Only two species of the section ( $L$. sinuatum and $L$. lobatum) are widespread in the Mediterranean region. Three species, L. beaumieranum, L. mouretii, and L. bonduellei (the last not included in this analysis), are Moroccan taxa, whereas the rest are from the Canary Islands. The section is defined by a unique syndrome of characters, but each of these characters is shared with another member of the Atlantic grade or other genera of Staticoideae. Regardless of the lack of strict morphological synapomorphies, monophyly of this group has never been ques- 
TABLE 3. Estimated ages (million years) of the marked nodes in Fig. 2.

\begin{tabular}{ccc}
\hline \hline Node & Parsimony & Maximum likelihood \\
\hline $\mathrm{a}$ & 18.84 & 16.94 \\
$\mathrm{~b}$ & 16.68 & 15.99 \\
$\mathrm{c}$ & 12.09 & 11.95 \\
$\mathrm{~d}$ & 9.10 & 9.06 \\
$\mathrm{e}$ & 7.16 & 6.74 \\
$\mathrm{f}$ & 7.89 & 8.50 \\
$\mathrm{~g}$ & 6.65 & 7.46 \\
$\mathrm{~h}$ & 8.42 & 8.88 \\
$\mathrm{i}$ & 6.68 & 7.18 \\
$\mathrm{j}$ & 11.02 & 11.60 \\
$\mathrm{k}$ & 8.31 & 9.55 \\
$\mathrm{l}$ & 6.59 & 7.54 \\
$\mathrm{~m}$ & 2.94 & 3.56 \\
$\mathrm{n}$ & 8.71 & 9.47 \\
\hline
\end{tabular}

tioned. Chemically, L. sect. Pteroclados is distinct from the rest of Limonium; they produce glycine betaine but lack Balanine betaine (Hanson et al., 1994), although this combination of chemical characters is also present in both subfamily Plumbaginoideae and Aegialitis. Boissier (1848) divided $L$. sect. Pteroclados into two subsections, Nobiles and Odontolepideae, neither of which is monophyletic in our analyses.
One of the clades includes only Canarian species belonging to L. subsect. Nobiles. The other combines one species of $L$. subsect. Nobiles from Tenerife (L. spectabile) with Moroccan and Mediterranean L. subsect. Odontolepideae. This result is inconsistent with the tree obtained using morphological and anatomical characters, which supported the monophyly of both subsections (Karis, 2004). This disagreement could be due to numerous causes, including the different sampling used in each analysis.

According to our tree, the Canarian clade composed of species of $L$. subsect. Nobiles diversified in the archipelago after a single migration. If the position of $L$. spectabile, included in L. subsect. Odontolepideae in our analyses, is an artifact instead of representing the true phylogeny of the group, the biogeographical patterns of $L$. sect. Pteroclados would be similar to other Canarian groups that are sister to North African and western Mediterranean species, although in this case some species of $L$. sect. Pteroclados have a wider Irano-Turanian distribution. The close proximity of the Canarian archipelago to the African continent could permit the migration and recolonization of taxa. Importantly, putatively natural populations of L. sinuatum and L. lobatum have been recently found in both Tenerife and Fuerteventura, confirming the occurrence of recent plant migrations between the archipelago and the African continent (Karis, 2004). Due to the winds and sea currents,

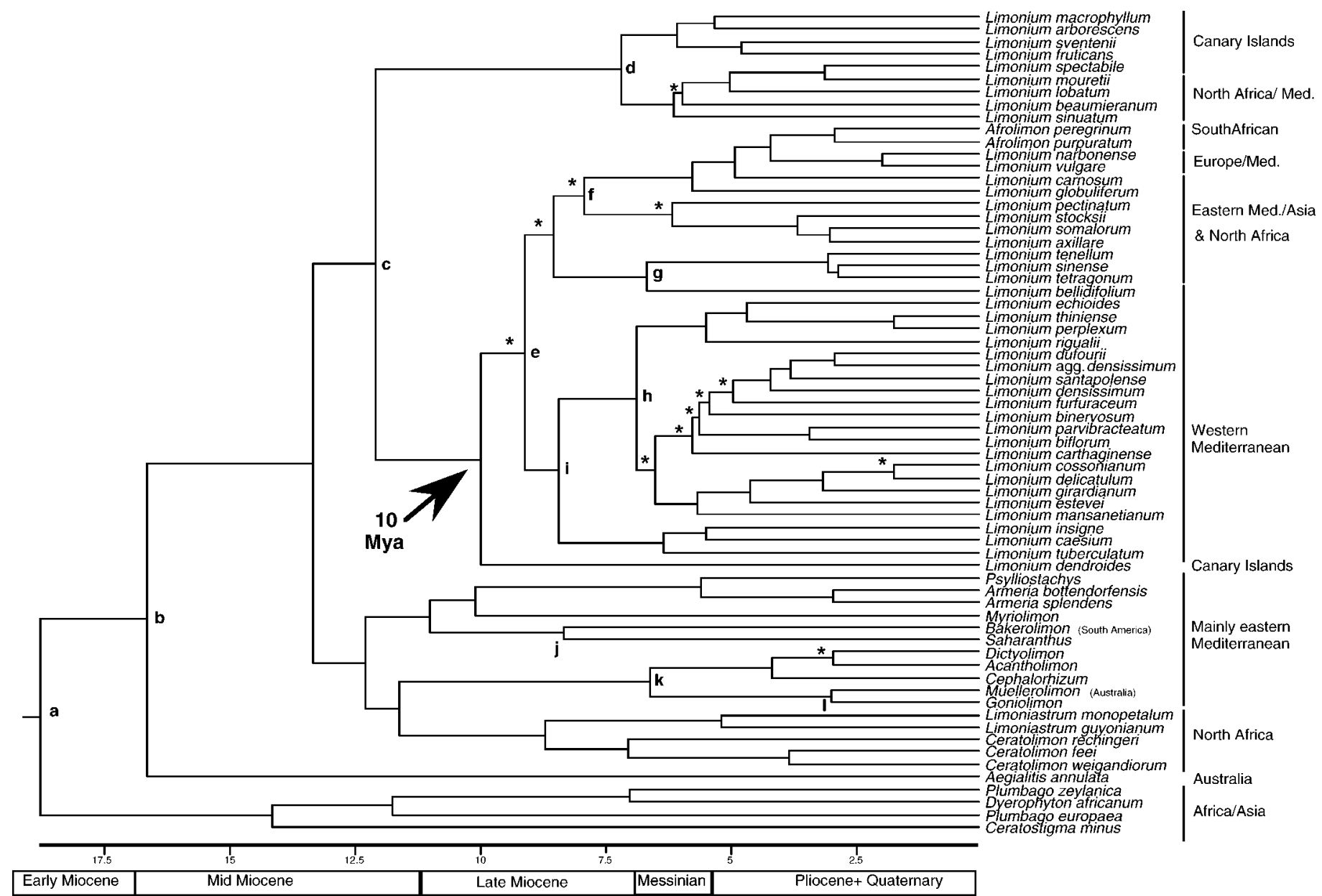

Fig. 2. Chronogram calibrated with the split between $L$. dendroides and the core Limonium clade at 10 million years ago (mya). Asterisks indicate clades collapsing in the strict consensus tree. 
the most likely general sources of colonizers are both North Africa and the Iberian Peninsula. The fact that the closest relatives of the Canarian species are in North Africa highlights the close relationships between the floras of these two regions (Sunding, 1979; Carine et al., 2004).

The next node in this Atlantic grade consists of the single species L. dendroides, described by Sventenius (1960) for a peculiar plant endemic to La Gomera (Canary Islands). Autapomorphies such as its arborescent habit (it reaches more than $3 \mathrm{~m}$ in height) and the presence of salt-excreting glands in the spikelet instead of on the leaves easily separate this species from any other taxon in Limonium. The lack of specific morphological characters that could relate this species to any other section of Limonium and the autapomorphies mentioned above lead Sventenius (1960) to create the monotypic section, Limoniodendron. The position in our cladograms confirms its phylogenetic isolation. Limonium dendroides shows the same chemical patterns as the rest of the genus (Hanson et al., 1994).

Most of the sections in the Atlantic grade (L. sects. Pteroclados, Ctenostachys, and Jovibarba) have fruits with circumscissile dehiscence (irregular in the rest of the genus). Unfortunately, mature fruits of $L$. dendroides have not been observed. The three known populations on La Gomera have only few individuals, and specimens propagated in Brest Botanic Garden (Brittany, France) and accessions at RBG Kew show the same incompatible combination of pollen/stigma. Although the plants flower regularly, they have not set seed. Circumscissile fruits should be regarded as plesiomorphic for Limonium. Another character absent in core Limonium that occurs in L. sects. Pteroclados, Jovibarba, and Ctenostachys is the presence of wings on the stems and/or spikelets, a character also present in other genera of Staticoideae (e.g., Goniolimon).

Core Limonium-The rest of the sections of Limonium ( $L$. sects. Plathymenium, Sphaerostachys, Circinaria, Limonium, Polyarthrion, and Siphonantha) form a clade that is supported by $\mathrm{BP}<50$. The sectional classification proposed by Boissier $(1848,1859)$ is largely not supported in our results.

The members of $L$. sect. Plathymenium form a clade comprising mainly Asian taxa, with species extending to Australia and islands in the Indian Ocean. Their sister taxon is L. bellidifolium, a diploid sexual member of $L$. sect. Limonium with a western Mediterranean distribution.

Only two sections from Boissier's corolla gamopetala still remain in Limonium, and the rest of sections are currently accepted as independent genera (Myriolimon, Psylliostachys, Bakerolimon, and Muellerolimon). As true members of $\mathrm{Li}$ monium, both sections have petals connate only at their base (Lledó et al., 2003), but they are not uniquely related to each other. The only known species of $L$. sect. Polyarthrion ( $L$. caesium and L. insigne) are endemics from eastern Spain and form a well-supported group with $L$. tuberculatum from the Sahara ( $L$. subsect. Hyalolepidae). The $t r n L-F$ region is missing for L. sect. Siphonantha (L. tubiflorum) from Egypt, and its position in the core-Limonium clade is not resolved, but its exclusion from the analysis did not change the position of the other terminals. In the combined analysis it is related to the North African species L. cylindrifolium but with $\mathrm{BP}<50$.

Limonium sect. Limonium, with six subsections, is the largest group in the genus. It includes most of the microspecies from the western Mediterranean, but also has members in America, Asia, and Australia. It is clearly polyphyletic in our analysis, although some subsections have a sound phylogenetic basis. Limonium sect. Limonium subsect. Genuinae is represented in the analyses by two closely related species, $L$. vulgare from Atlantic Europe (the type of the genus) and $L$. narbonense with a western Mediterranean distribution. They form a poorly supported clade with $L$. carnosum $(L$. subsect. Sarcophyllae), L. globuliferum (L. sect. Sphaerostachys), and two representatives of Afrolimon ( $=L$. sect. Circinaria). According to these results, the distinct generic status of Afrolimon cannot be maintained. Both L. carnosum and L. globuliferum are northwestern African plants, whereas L. subsect. Genuinae is a widespread group that has reached America.

The clade sister to the rest of the core Limonium group is formed by three species of $L$. subsect. Sarcophyllae. Two other species of this subsection are placed elsewhere in the tree: $L$. carnosum is related to $L$. sect. Circinaria (= Afrolimon), and L. cylindrifolium groups with L. tubiflorum and L. biflorum. Limonium subsect. Sarcophyllae has a continuous distribution centered in the Middle East, reaching the Indian Ocean in the east and the Caucasus in the west. It has been accepted as one of the most morphologically homogeneous groups in the genus (Baker, 1953b), but both anatomy and molecular data demonstrate their polyphyly. Characters such as the presence of spindle-shaped foliar sclereids (Bokahri, 1970) are supposed synapomorphies of $L$. subsect. Sarcophyllae. Two members of the section, although similar morphologically, are anatomically different: L. carnosum lacks foliar sclereids (few sections of Limonium lack them), and L. cylindrifolium has a unique filiform type of sclereids not present elsewhere in the genus.

Although phylogenetic relationships among some Limonium microspecies have been assessed using both plastid and nuclear markers (Palacios et al., 2000), their phylogenetic position within the family and the genus as a whole has not yet been established. The microspecies from eastern Spain included in these analyses belong to three subsections of $L$. sect. Limonium (Densiflorae, Dissitiflorae, and Steirocladae). They form a clade subsequently divided in two groups. The smaller group has a high BP (92) and is composed of sexual species ( $L$. echioides, $2 n=18$ ) and triploids (L.thiniense, $2 n=26)$. All these species are characterized by their small size; L. echioides is one of the few annuals in Limonium, L. thiniense and $L$. perplexum are cryptophytes, and $L$. rigualii is a small hemicryptophyte; they also share unique floral characters such as the recurrent calyx ribs. The larger of these two clades has a low BP, and it is again composed of two clades, both of them a mixture of diploids and polyploids. The diploids with $2 n=$ 16 (L. cossonianum and L. estevei) are in a clade separate from those with $2 n=18$ ( $L$. furfuraceum and $L$. carthaginense). Several authors have hypothesized that the two basic chromosome numbers correspond to two independent groups that hybridized and produced several polyploid series (Dolcher and Pignatti, 1971). Chromosome numbers such as $2 n=23,25$, 26 and 27 could be explained if species with both basic numbers took part in the original hybridization followed by dysploid reductions after the event (Erben, 1979). In his taxometric analysis of western European Limonium spp., Ingrouille (1984) reported that sexual and apomictic taxa had a tendency to cluster separately and suggested that the apomictic species evolved independently from the sexual ones. Our results do not support this hypothesis, since apomictic triploids and sexual diploids are mixed in the tree, although sexuals with $2 n$ $=16$ and $2 n=18$ are in different clades, suggesting that both chromosome series evolved independently. Due to the mater- 
nal inheritance of plastids, potential reticulation is not detected, but it nonetheless appears that apomicts have arisen repeatedly from sexual taxa.

Molecular clock-Our ages for the split between subfamilies Plumbaginoideae and Staticoideae are more recent than the estimates given by Wikström et al. (2003), in which the angiosperm phylogenetic tree was calibrated using a fossil placed on the node between Fagales and Cucurbitales (84 mya). Their estimated age for the split between Plumbago and Limonium was between 28 mya (MP) and 32 mya (ML), with an error of 3 mya, much older than the 18-16 mya obtained in our analyses. The discrepancies could be due to numerous causes, and the most likely is a calibration point (in eurosid I) distant from the Caryophyllales (clades according to APG, 2003). In studies in which sampling includes taxa from lineages with different rates of molecular evolution, age estimates can be biased by high rates of evolution in some taxa (Sanderson and Doyle, 2001). Rates are expected to be more homogeneous in younger and smaller groups (Sanderson and Doyle, 2001). Also, a calibration point within the family or close to the focus of study is more likely to provide more accurate estimates. It is important to note that there are few fossils for Plumbaginaceae that are relevant for establishing the ages of clades, but the possibility of calibrating the tree using the age of a volcanic island that is close to the mainland can also be a source of error, most likely caused by the taxon in question somewhere else before it colonized the island and then became extinct in its original home. This would lead to underestimates of ages for all nodes, such as those reported here. Thus, our estimates are minimal ages that could realistically be somewhat greater.

Our analysis indicates ages that, although younger than the previous estimate age of the family (Wikström et al., 2001, 2003), are nonetheless in accordance with major geological and climatic events that took place in the Mediterranean and Eurasia in the last 20 million years. According to the dates shown in Fig. 2, the radiation within the apomictic/sexual complex in Limonium started around 6 mya, which occurred at the same time as one of the most drastic changes that has taken place in the Mediterranean basin. According to the Messinian model (Hsü et al., 1973, 1977; Bocquet et al., 1978), the Mediterranean Sea suffered several cycles of desiccation and increasing aridity in the late Miocene (5.5-4.5 mya). The process started with the closure of the Straits of Gibraltar about 5.5 mya, which subsequently opened and closed several times in the following million years. The lower water levels allowed new transcontinental connections (Africa-Europe; Asia-Europe) as the newly emerged land was colonized. Saline steppes were created and submerged in several cycles, allowing the isolation and speciation of saline-tolerant plants such as $\mathrm{Li}$ monium. Adaptive radiations are usually seen as cladograms with a bush-type shape. This is not exactly the case for the Limonium apomictic/sexual group (clade h, Fig. 2), although we have not included the hundreds of taxa that have been described in the Mediterranean basin. Although divergence and cladogenesis in the Late Miocene occurred at a slow pace, during the Messinian cladogenesis in Limonium accelerated (Fig. 2), indicating that the speciation process was much faster during the Messinian than in the middle Miocene.

During the middle Miocene (approximately 12 mya) the northern part of Africa was occupied by a subtropical woodland savannah (Quézel, 1978). These climatic conditions pre- vented the colonization of xerophytic plants such as Limonium, but the climate was probably suitable for climbers. According to the dates on our tree (Fig. 2), Plumbaginoideae were diversifying at that time. The extant members of this subfamily are African climbers with a few Asiatic species. They were probably pushed further south when the arid conditions of the late Miocene prevailed in the northern part of Africa.

Within Staticoideae, diversification occurred earlier in clades formed by Asiatic montane genera, less affected by the late Miocene climate change than taxa from lower elevations. The decrease in the level of the Mediterranean produced a land connection that allowed the expansion of Asiatic species westwards. These ideas fit the current view that migration patterns in the Mediterranean have followed an east-west direction, with eastern groups generally being older than the western ones (Quézel, 1978).

The Macaronesian flora has a close connection with western Africa and the Mediterranean, although some floristic elements are related to more remote regions such as East Africa and Asia (Andrus et al., 2004). The two most likely sources of colonizers are North Africa and the southern Iberian Peninsula, and colonization patterns follow an east-west direction, from the mainland to the islands. Despite the short distance to the continent, the archipelago is a hot spot of endemicity (Francisco-Ortega et al., 2000), and radiations have taken place in most of the families present in the islands, although the biogeography of each group is unique. Taxa including Sonchus, Echium, and the Bencomia alliance radiated after a single colonization event, but multiple colonizations have been demonstrated for Ilex, Lavatera, and Convolvulus (see review in Carine et al., 2004). According to our data, Limonium reached the Canary Islands at least three times. The oldest migration corresponds to $L$. sect. Pteroclados about 7.5 mya. We have assumed that $L$. dendroides ( $L$. sect. Limoniodendron) arose in La Gomera shortly after the formation of the island and have used this age to calibrate the phylogenetic tree. Limonium sect. Ctenostachys, even if mainly African, contains species that grow in both the mainland and islands, for example L. pectinatum, but none of the species are Canarian endemics. The distribution of $L$. pectinatum can be seen as recent colonization similar to L. sinuatum and L. lobatum in Fuerteventura, with island populations that have not been isolated for long enough for speciation to have occurred. It is necessary to stress that the aim of this calibration is not to address the biogeographical patterns of Limonium in the Canary Islands as we have only included in this analysis species occurring on three islands (Tenerife, Gran Canaria, and La Gomera). Rather, the aim here is to date the main events in the family, such as migrations to the Southern Hemisphere and radiations of different groups of Limonium in the Mediterranean and Macaronesia.

The family has a center of diversity in Eurasia, and migrations to other continents took place at different times. Aegialitis, with clear characters that relate it to Staticoideae, was isolated in Australia and southern India at the beginning of the mid-Miocene, before the characteristic pollen/stigma dimorphism evolved in the family (Lledó et al., 2001).

There are also at least two independent migrations to the New World. South American Bakerolimon is an older migration that took place about 8 mya (Fig. 3). Several species of Limonium have been described from the coastal Mediterranean climate areas of America. These taxa show morphological features that relate them to the northern species of $L$. subsect. Genuinae (Baker, 1953b). American species of Limonium have 
not been included in this analysis, but their close connection with northern European species has been hypothesized (Baker, 1953b). The L. vulgare clade is much younger than Bakerolimon, and if the American Limonium species are related to $L$. vulgare then the two American groups are not closely related.

In addition to the mangrove genus Aegialitis, two more groups of Staticoideae are present in Australia, Muellerolimon in the west and L. sect. Plathymenium in the east. Both groups migrated separately in the Miocene. Limonium sect. Sarcophyllae is the eastern-most clade in Limonium, with species distributed in Asia ( $L$. sinense), islands in the Indian Ocean (L. tetragonum), and Australia (L. australe; not sampled here). Muellerolimon is sister to Goniolimon and related to other eastern Mediterranean and Irano-Turanian genera (Acantholimon, Dictyolimon, and Cephalorhizum).

Our results give a sound phylogenetic framework for a reclassification of Limonium as a whole. Limonium is divided into two well-supported clades, corresponding to $L$. sect. Pteroclados and the rest of the genus. These two groups can be accepted as L. subg. Pteroclados and L. subg. Limonium (including the rest of the sections), in a system similar to that proposed by Pignatti (Table 1). Rearranging the sectional classification is more complicated, and probably more taxa should be sampled before this is done. Some sections are monophyletic and could remain as they are (e.g., L. sect. Plathymenium), but a large number of clades do not correspond to any previously described taxon. At this stage, any attempt to classify Limonium at lower taxonomic levels will only increase taxonomic confusion. In addition, the largest groups of $\mathrm{Li}$ monium are composed of populations with a hybrid origin that have been fixed by apomixis. These agamospermous groups do not have a simple hierarchical system. If hybridization is a major feature of this radiation, these species are in fact related to more than one phylogenetic line. Including them in an enlarged $L$. subg. Limonium together with sexual species seems to be the most appropriate solution.

\section{LITERATURE CITED}

Andrus, N., J. Trusty, A. Santos-Guerra, R. K. Jansen, and J. FranCISCO-ORTEGA. 2004. Using molecular phylogenies to test phytogeographical links between East/South Africa-southern Arabia and the Macaronesian Islands-a review and the case of Vierea and Pulicaria section Vieraeopsis (Asteraceae). Taxon 53: 333-346.

APG. 2003. An update of the Angiosperm Phylogeny Group Classification for the orders and families of flowering plants: APG II. Botanical Journal of the Linnean Society 141: 399-436.

BAKER, H. G. 1948. Dimorphism and monomorphism in the Plumbaginaceae. I. A survey of the family. Annals of Botany 12: 207-219.

BAKER, H. G. 1953a. Dimorphism and monomorphism in the Plumbaginaceae. II. Pollen and stigmata in the genus Limonium. Annals of Botany 17: 433-445.

BAKER, H. G. 1953b. Dimorphism and monomorphism in the Plumbaginaceae. III. Correlation of geographical distribution patterns with dimorphism and monomorphism in Limonium. Annals of Botany 17: 615-627.

BAKER, H. G. 1966. The evolution, functioning, and breakdown of heteromorphic incompatibility systems. I. The Plumbaginaceae. Evolution 20: 349-368.

Bocquet, G., B. Wilder, And H. KIEfer. 1978. The Messinian Model-a new outlook for the floristics and systematics of the Mediterranean area. Candollea 33: 269-287.

Boissier, E. 1848. Plumbaginales. In A. P. de Candolle [ed.], Prodromus systematis naturalis regni vegetabilis, 12: 617-696. Treuttel et Wurz, Paris, France.

BoISSIER, E. 1859. Diagnoses plantarum orientalium novarum. Ser. 2, 4: 6171. Paris, France.

BOKHARI, M. H. 1970. Morphology and taxonomic significance of foliar sclereids in Limonium. Notes of the Royal Botanic Garden Edinburgh 30: 43-53.

Carine, M. A., S. J. Russell, A. Santos-Guerra, and J. Francisco-OrTEGA. 2004. Relationships of the Macaronesian and Mediterranean floras: molecular evidence for multiple colonizations into Macaronesia and back-colonization of the continent in Convolvulus (Convolvulaceae). American Journal of Botany 91: 1070-1085.

Chase, M. W., AND H. G. Hills. 1991. Silica gel: an ideal material for field preservation of leaf samples for DNA studies. Taxon 40: 215-220.

Cowan, R., M. J. Ingrouille, AND M. D. Lledó. 1998. The taxonomic treatment of agamosperms in the genus Limonium Mill. (Plumbaginaceae). Folia Geobotanica 33: 353-366.

Crespo, M. B., AND M. D. Lledó. 2000. Two new North African genera related to Limoniastrum (Plumbaginaceae). Botanical Journal of the Linnean Society 132: 165-174.

Dolcher, T., AND S. PignAtTI. 1971. Un'ipotesi sull'evoluzione dei Limonium dei bacino del Mediterraneo. Giornale Botanico Italiano 105: 95107.

ERBEN, M. 1979. Karyotype differentiation and its consequences in Mediterranean Limonium. Webbia 34: 409-417.

Erben, M. 1993. Limonium Miller. In S. Castroviejo, C. Aedo, S. Cirujano, M. Laínz, P. Montserrat, R. Morales, F. Muñoz Garmendia, C. Navarro, J. Paiva, and C. Soriano [eds.], Flora iberica, vol. 2, 2-143. Real Jardín Botánico, CSIC (Consejo Superior de Investigaciones Científicas), Madrid, Spain.

Fay, M. F., C. Bayer, W. S. Alverson, A. Y. de Bruinn, and M. W. Chase. 1998. Plastid $r b c L$ sequence data indicate a close affinity between Diegodendron and Bixa. Taxon 47: 43-50.

FELSENSTEIN, J. 1981. Evolutionary trees from DNA sequences-a maximum likelihood approach. Journal of Molecular Evolution 17: 386-376.

FELSENSTEIN, J. 1985. Confidence limits on phylogenies: an approach using the bootstrap. Evolution 39: 783-791.

Francisco-Ortega, J., A. Santos-Guerra, S. C. Kimand, and D. J. CRAWFORD. 2000. Plant genetic diversity in the Canary Islands: a conservation perspective. American Journal of Botany 87: 909-919.

Godwin, H. 1956. The history of the British flora. A factual basis for phytogeography. Cambridge University Press, Cambridge, UK.

Goldblatt, P., V. Savolainen, O. Porteous, I. Sostaric, M. Powell, G. Reeves, J. C. Manning, T. G. Barraclough, and M. W. Chase. 2002. Radiation in the Cape flora and the phylogeny of peacock irises Moraea (Iridaceae) based on four plastid DNA regions. Molecular Phylogenetics and Evolution 25: 341-360.

Greuter, W., J. McNeill, F. R. Barrie, H.-M. Burdet, V. Demoulin, T. S. Filgueiras, D. H. Nicolson, P. C. Silva, J. E. Skog, P. Trehane, N. J. Turland, and D. L. Hawksworth [eds.]. 2000. International code of botanical nomenclature (Saint Louis Code). Koeltz Scientific Books, Königstein, Germany [Regnum Vegetabile 138].

Hanson, A. D., B. Rathinassabapathi, J. Rivoal, M. Burnet, M. O. Dillon, AND D. A. Gage. 1994. Osmoprotective compounds in the Plumbaginaceae: a natural experiment in metabolic engineering of stress tolerance. Proceedings of the National Academy of Sciences, USA 91: 306-310.

Harborne, J. B. 1967. Comparative biochemistry of the flavonoids. IV. Correlations between chemistry, pollen morphology and systematics in the family Plumbaginaceae. Phytochemistry 6: 1415-1428.

Hooker, J. D. 1876. Plumbaginaceae. In G. Bentham and J. D. Hooker [eds.], Genera plantarum ad exemplaria imprimis in herbariis Kewensibus servata, vol. 2, 623-628. Reeve \& Co., London, UK.

Hsü, J. K., L. Montadert, D. Bernoulli, M. B. Cita, A. Erickson, R. E. Garrison, R. B. Hidd, F. Mèlierés, C. Müller, And R. Wright. 1977. History of the Mediterranean salinity crisis. Nature 267: 399-403.

Hsü, J. K., W. B. F. Ryan, And M. B. Cita. 1973. Late Miocene desiccation of the Mediterranean. Nature 242: 240-244.

INGRouILLE, M. J. 1984. A taxometric analysis of Limonium (Plumbaginaceae) in western Europe. Plant Systematics and Evolution 147: 103-118.

Juan, C., C. E. Emerson, P. Oromí, And G. M. Hewitt. 2000. Colonization and diversification: towards a phylogeographic synthesis for the Canary Islands. Trends in Ecology and Evolution 15: 104-109.

KARIS, P. O. 2004. Taxonomy, phylogeny and biogeography of Limonium sect. Pteroclados (Plumbaginaceae), based on morphological data. Botanical Journal of the Linnean Society 144: 461-482.

Kelchner, S. A. 2000. The evolution of non-coding chloroplast DNA and 
its application in plant systematics. Annals of the Missouri Botanical Garden 87: 482-498.

KubITZKI, K. 1993. Plumbaginaceae. In K. Kubitzki, J. G. Rohwer, and V. Bittrich [eds.], The families and genera of vascular plants, vol. 2, 523530. Springer, Berlin, Germany.

LiNCZEVSKI, I. A. 1968. Tentamentum systematis ordinis Plumbaginalium Lindl. Novitates Systematicae Plantarum Vascularium (Leningrad). 1968: 171-177.

LinCZEVSKI, I. A. 1982. A new Australian genus, Muellerolimon (Limoniaceae). Botanicheskii Zhurnal, Moscow and Leningrad 67: 675-678.

Lledó, M. D., M. B. Crespo, K. M. Cameron, M. F. Fay, and M. W. CHASE. 1998. Systematics of Plumbaginaceae based upon cladistic analysis of $r b c L$ sequence data. Systematic Botany 23: 21-29.

Lledó, M. D., M. B. Crespo, A. V. Cox, M. F. Fay, and M. W. Chase. 2000. Polyphyly of Limoniastrum (Plumbaginaceae): evidence from DNA sequences of plastid $r b c L$ and $\operatorname{trn} L$ intron and $\operatorname{trn} L-F$ intergene spacer. Botanical Journal of the Linnean Society 132: 175-191.

Lledó, M. D., M. ERBEN, AND M. B. CRESPo. 2003. Myriolepis, a new genus segregated from Limonium (Plumbaginaceae). Taxon: 52: 67-73.

Lledó, M. D., M. Erben, And M. B. Crespo. In press. Myriolimon, a new name for the recently described Myriolepis. Taxon.

Lledó, M. D., P. O. Karis, M. B. Crespo, M. F. Fay, and M. W. Chase. 2001. Phylogenetic position and taxonomic status of the genus Aegialitis and subfamilies Staticoideae and Plumbaginoideae (Plumbaginaceae): evidence from plastid DNA sequences and morphology. Plant Systematics and Evolution 229: 107-124.

Palacios, C., J. A. Rosselló, and F. González Candelas. 2000. Study of the evolutionary relationships among Limonium species (Plumbaginaceae) using nuclear and cytoplasmic molecular markers. Molecular Phylogenetics and Evolution 14: 232-249.

PAX, F. 1889. Plumbaginaceae. In A. Engler and K. Prantl [eds.], Die Natürlichen Pflanzenfamilien, vol. 4, 116-125. W. Englemann, Leipzig, Germany.

Pignatti, S. 1971. Studi sui Limonium, VIII. In V. H. Heywood [ed.], Florae Europaea. Notulae systematicae ad flora Europaeam spectantes. Botanical Journal of the Linnean Society 64: 353-381.

Pignatti, S. 1972. Limonium. In T. G. Tutin, V. H. Heywood, N. A. Burges, D. A. Valentine, S. M. Walters, D. A. Webb, and D. M. Moore [eds.],
Flora Europaea, vol. 3, 38-50. Cambridge University Press, Cambridge, UK.

Posada, D., AND K. A. Crandall. 1998. Modeltest: testing the model of DNA substitution. Bioinformatics 14: 817-818

QuÉzeL, P. 1978. Analysis of the flora of the Mediterranean and Saharan Africa. Annals of the Missouri Botanical Garden 65: 479-534.

Rambaut, A., AND M. Charleston. 2000. TreeEdit version $1.0 \alpha$. Available at website http://evolve.zoo.ox.ac.uk/software/TreeEdit/TreeEdit.html.

Rechinger, K. H. 1974. Plumbaginaceae. In K. H. Rechinger [ed.], Flora Iranica 108. Akademische Druck- und Verlagsanstalt, Graz, Austria.

Richardson, J. E., F. M. Weitz, M. F. FAY, Q. C. B. Cronk, H. P. Linder, G. ReEves, AND M. W. Chase. 2001. Rapid and recent origin of species richness in the Cape flora of South Africa. Nature 412: 181-183.

Salamin, N., M. W. Chase, T. R. Hodkinson, and V. Savolainen. 2003. Assessing internal support with large phylogenetic DNA matrices. Molecular Phylogenetics and Evolution 27: 528-539.

SANDERSON, M. J. A. 1997. A nonparametric approach to estimating divergence times in the absence of rate constancy. Molecular Biology and Evolution 14: 1218-1232.

SAnDerson, M. J. A., AND J. A. Doyle. 2001. Sources of error and confidence intervals in estimating the age of the angiosperms from $r b c L$ and 18S rDNA data. American Journal of Botany 88: 1499-1516.

Savolainen, V., P. Cuénoud, R. Spichiger, M. D. P. Martínez, M. CrèveCOEUR, AND J. F. MANEN. 1995. The use of herbarium specimens in DNA phylogenetics: evaluation and improvement. Plant Systematics and Evolution 197: 87-98.

Sunding, P. 1979. Origins of the Macaronesian flora. In D. Bramwell [ed.], Plants and islands. Academic Press, London, UK.

Sventenius, E. R. S. 1960. Additamentum ad floram canariensem. Matritri Hispanicum Institutum, Madrid, Spain.

SwOFFORD, D. L. 2003. PAUP*: phylogenetic analysis using parsimony (*and other methods). Version 4. Sinauer, Sunderland, Massachusetts, USA.

Wikström, N., V. Savolainen, AND M. W. Chase. 2001. Evolution of the angiosperms: calibrating the family tree. Proceedings of the Royal Society, Series B 268: 2211-2220.

Wikström, N., V. Savolainen, and M. W. Chase. 2003. Angiosperm divergence times: congruence and incongruence between fossils and sequence divergence estimates. In C. J. Donoghue and M. P. Smith [eds.], Telling the evolutionary time: molecular clocks and the fossil record. Boca Raton, Florida, USA. 